\title{
Phylogenetic relationships and systematic position of the families Cortrematidae and Phaneropsolidae (Platyhelminthes: Digenea)
}

\author{
Gerard Kanarek $^{1}$, Grzegorz Zaleśny ${ }^{2}$, Jiljí Sitko $^{3}$ and Vasyl V. Tkach ${ }^{4}$ \\ ${ }^{1}$ Ornithological Station, Museum and Institute of Zoology, Polish Academy of Sciences, Gdańsk, Poland; \\ ${ }^{2}$ Institute of Biology, Wrocław University of Environmental and Life Sciences, Wrocław, Poland; \\ ${ }^{3}$ Comenius Museum, Přerov, Czech Republic; \\ ${ }^{4}$ Department of Biology, University of North Dakota, Grand Forks, North Dakota, USA
}

\begin{abstract}
The systematic position and phylogenetic relationships of the family Cortrematidae Yamaguti, 1958 have always been controversial. In the present study, the phylogenetic relationships of this family and its constituent genera and families within the superfamily Microphalloidea were evaluated using previously published and newly obtained sequences of 28S rDNA of Cortrema magnicaudata (Bykhovskaya-Pavlovskaya, 1950) (Cortrematidae), Phaneropsolus praomydis Baer, 1971 and Microtrema barusi Sitko, 2013 (Phaneropsolidae). Results clearly demonstrate that the genus Cortrema Tang, 1951 is closest to Gyrabascus Macy 1935, both genera forming one of the clades within the family Pleurogenidae in the superfamily Microphalloidea and sharing several important morphological features. Thus, the family Cortrematidae should be considered among synonyms of the Pleurogenidae. Based on the analysis of morphology, C. corti Tang, 1951, C. testilobata (Bykhovskaya-Pavlovskaya, 1953) and C. niloticus Ashour, Ahmed et Lewis, 1994 are considered junior synonyms of C. magnicaudata. The phylogenetic position of P. praomydis as a familylevel branch not showing close relationships with other families of the Microphalloidea, supports the status of the Phaneropsolidae as an independent family. The genus Parabascus Looss, 1907 previously considered within the Phaneropsolidae clearly belongs to the Pleurogenidae. In addition, the molecular phylogeny has demonstrated that the recently described phaneropsolid Microtrema barusi belongs to the microphallid genus Microphallus Ward, 1901. Therefore, Microtrema Sitko, 2013 is considered a junior synonym of Microphallus. Our analysis has also confirmed the status of Collyriclidae as a family within the Microphalloidea. Not yet sequenced representatives of other families within the Microphalloidea (e.g. Anenterotrematidae, Eumegacetidae, Renschtrematidae, Stomylotrematidae, etc.) need to be included in future molecular phylogenetic studies to better unravel the taxonomic structure and content of this diverse digenean superfamily.
\end{abstract}

Keywords: Trematoda, Plagiorchiida, Microphalloidea, Cortrema, 28S rDNA, molecular phylogeny, taxonomy

The systematic position of the family Cortrematidae Yamaguti, 1958 has always been contentious. This small family contains a single genus Cortrema Tang, 1951 that includes only four species parasitising the posterior parts of the digestive tract and bursa Fabricii of passeriform birds in Europe, Asia and Africa. Tang (1951) established Cortrema to accommodate Cortrema corti Tang, 1951 described from the bursa Fabricii of Chinese tree sparrow, Passer montanus saturatus Stejneger. Due to the general similarity of internal organ topology between $C$. corti and another avian trematode, Collyriclum faba (Bremser, 1831), Tang (1951) placed his new genus in the family Troglotrematidae Odhner, 1914, which included Collyriclum Kossack, 1911 at the time.

Yamaguti (1958) erected a new family Cortrematidae for Cortrema and Khotenovskii (1961) included in Cortrema two additional species described from passeriform birds in the former USSR, namely Renicola magnicaudata Bykhovskaya-Pavlovskaya, 1950 and Leyogonimus testilobatus Bykhovskaya-Pavlovskaya, 1953. Renicola magnicaudata was described from the kidneys of a barn swallow Hirundo rustica Linnaeus sampled in western Siberia (Bykhovskaya-Pavlovskaya 1950).

Khotenovskii (1961) concluded that several morphological features of $R$. magnicaudata, such as the genital pore at the posterior extremity, long Laurer's canal and tubular excretory vesicle, are not consistent with the diagnosis of Renicola Cohn, 1904 and transferred this species into Cortrema. Khotenovskii (1961) believed that the unusual localisation of C. magnicaudata (BykhovskayaPavlovskaya, 1950) in the kidneys reported in the original description by Bykhovskaya-Pavlovskaya (1950) could be explained by damage of the intestine resulting from a gunshot.

Address for correspondence: G. Kanarek, Ornithological Station, Museum and Institute of Zoology, Polish Academy of Sciences, ul. Nadwiślańska 108, 80-680 Gdańsk, Poland. Phone: + 485830807 59; Fax: + 485830809 82; E-mail: kanarek@miiz.waw.pl 
The second species, Leyogonimus testilobatus, was described based on several specimens found in the lower intestine of Eurasian jays Garrulus glandarius Linnaeus collected near Saint Petersburg, Russia (BykhovskayaPavlovskaya 1953). Based on his re-examination of type specimens of L. testilobatus, Khotenovskii (1961) demonstrated that this species belonged to Cortrema. Most recently, Ashour et al. (1994) described Cortrema niloticus Ashour, Ahmed et Lewis, 1994 from the bursa Fabricii of an Egyptian house sparrow Passer domesticus niloticus Nicoll et Bonhote in Egypt.

Based on several morphological features of adult digeneans such as the location of the ventral sucker, the shape and location of the excretory vesicle, the location of the testes, the presence of the receptaculum seminis and Laurer's canal, the structure and location of vitelline follicles, and the degree of development of the uterus in gravid specimens, Khotenovskii (1961) lowered the status of Cortrematidae to subfamily within the Lecithodendriidae Lühe, 1901. Subsequently, Odening (1964a,b) placed Cortrematidae in the superfamily Microphalloidea Ward, 1901 together with Allassogonoporidae Skarbilovich, 1948, Anenterotrematidae Yamaguti, 1958, Eumegacetidae Travassos, 1922, Lecithodendriidae Lühe, 1901, Microphallidae Ward, 1901, Pleurogenidae Looss, 1899 and Stomylotrematidae Poche, 1926.

In Odening's opinion these families (except the Microphallidae) constitute a 'Lecithodendrioiden Komplex', indicating their close similarity. Therefore, in his subsequent publication, Odening (1971) created a new superfamily Lecithodendrioidea Odening, 1971 including, in addition to the above-mentioned families, the Anchitrematidae Mehra, 1935, Cryptotropidae Khotenovsky, 1965 and Urotrematidae Poche, 1926.

In the same year, Yamaguti (1971) placed the Cortrematidae in the superfamily Troglotrematoidea Faust, 1929. In contrast, Sharpilo and Iskova (1989) accepted Odening's systematic arrangement and considered the Cortrematidae within the Lecithodendrioidea. In yet another twist of convoluted systematic history of Cortrema in the most recent classification, the Cortrematidae was regarded as a family within the superfamily Gorgoderoidea Looss, 1899 (see Blair and Barton 2008). However, Bray and Blair (2008) emphasised that the Gorgoderoidea did not possess any outstanding autapomorphies in morphology or life histories.

The above historical account indicates the need of a phylogenetic analysis based on an additional, independent set of characters to clarify the phylogenetic affinities of Cortrema and stabilise its systematic position. All previous studies dealing with the systematic position of the Cortrematidae were based exclusively on morphological and life history characteristics. At the same time, the molecular framework of the superfamily Microphalloidea and related digenean lineages has been established in pre- vious molecular phylogenetic studies (Olson et al. 2003, Tkach et al. 2003, Henneberg and Literák 2013). In the present work, we evaluate the phylogenetic relationships of the family Cortrematidae using newly obtained partial sequences of the nuclear large ribosomal subunit DNA of Cortrema magnicaudata collected from a barn swallow, Hirundo rustica in the Czech Republic. The phylogenetic position of Cortrema is discussed, and several changes in the system of the Microphalloidea and some of its constituent genera and families are proposed.

\section{MATERIALS AND METHODS}

\section{Specimen collecting}

Seventy one specimens of Cortrema magnicaudata were found in the caeca of an adult male of H. rustica Linnaeus found dead on 11 May 2013 near Záhlinice (49 $17^{\circ} 06^{\prime \prime N}$; 17²8'41"E), Kroměříž District, Moravia, Czech Republic. Worms were rinsed in tap water and fixed in $70 \%$ ethanol. Some of the collected trematodes were stained in borax carmine, dehydrated in ethanol series, cleared in clove oil, mounted in Canada balsam and identified according to Khotenovskii (1961). Voucher specimens have been deposited in the Polish Collection of Parasitic Helminths, Museum of Natural History, Wrocław, Poland, Coll. Nos. 144271-144282, Comenius Museum, Přerov, Czech Republic, Coll. No. P-P-1868/12 and in the Helminthological Collection of the Institute of Parasitology, Biology Centre ASCR, České Budějovice, Czech Republic, Coll. No. IPCAS D-706.

To complement the phylogenetic analysis we have also sequenced a specimen of Phaneropsolus praomydis Baer, 1971 and a specimen of Microtrema barusi Sitko, 2013. Phaneropsolus praomydis were collected on 29 October 2009 from Rhabdomys dilectus De Winton in Rumphi District, Nyika National Park,

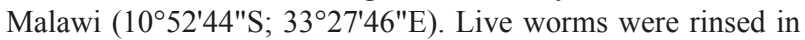
saline, killed with hot water and fixed in $70 \%$ ethanol suitable for both morphological and molecular study. Voucher specimen of $P$. praomydis stained with alum carmine and mounted in Damar Gum was deposited in the collection of the Harold W. Manter Laboratory (Lincoln, Nebraska, USA) under catalogue number HWML 49999. The rodent host specimen is deposited in the collection of the Field Museum of Natural History (Chicago, Illinois, USA) under accession number FMNH 1818404. Microtrema barusi were collected on 2 April 2010 from dunnock Prunella modularis (Linnaeus) in Záhlinice, $15 \mathrm{~km}$ south to Přerov, Kroměříž District, Moravia, Czech Republic. Worms were fixed in $70 \%$ ethanol. Total mounted specimens stained with iron acetocarmine were deposited in the collection of the Comenius Museum Prerov, Czech Republic, under accession numbers P-P-1868/16/1-30, and in the collection of the Natural History Museum, London, UK, under accession number BMNH 2012.1.19.1. For details see original description (Sitko 2013).

\section{DNA extraction, amplification and sequencing}

Genomic DNA was extracted from single worms of C. magnicaudata, P. praomydis and M. barusi using DNeasy Blood and Tissue Kit (Qiagen, Hilden, Germany) following the manufacturer's protocol. The 5' end of the 28S rRNA gene (lsrDNA) was amplified using forward primer- dig 12 (5'-AAG CAT ATC ACT AAG CGG-3') and reverse primer 1500R (5'-GCT ATC CTG AGG GAA ACT TCG-3') (Tkach et al. 2003). PCR reactions were performed in a total volume of $25 \mu \mathrm{l}$ using Taq polymer- 


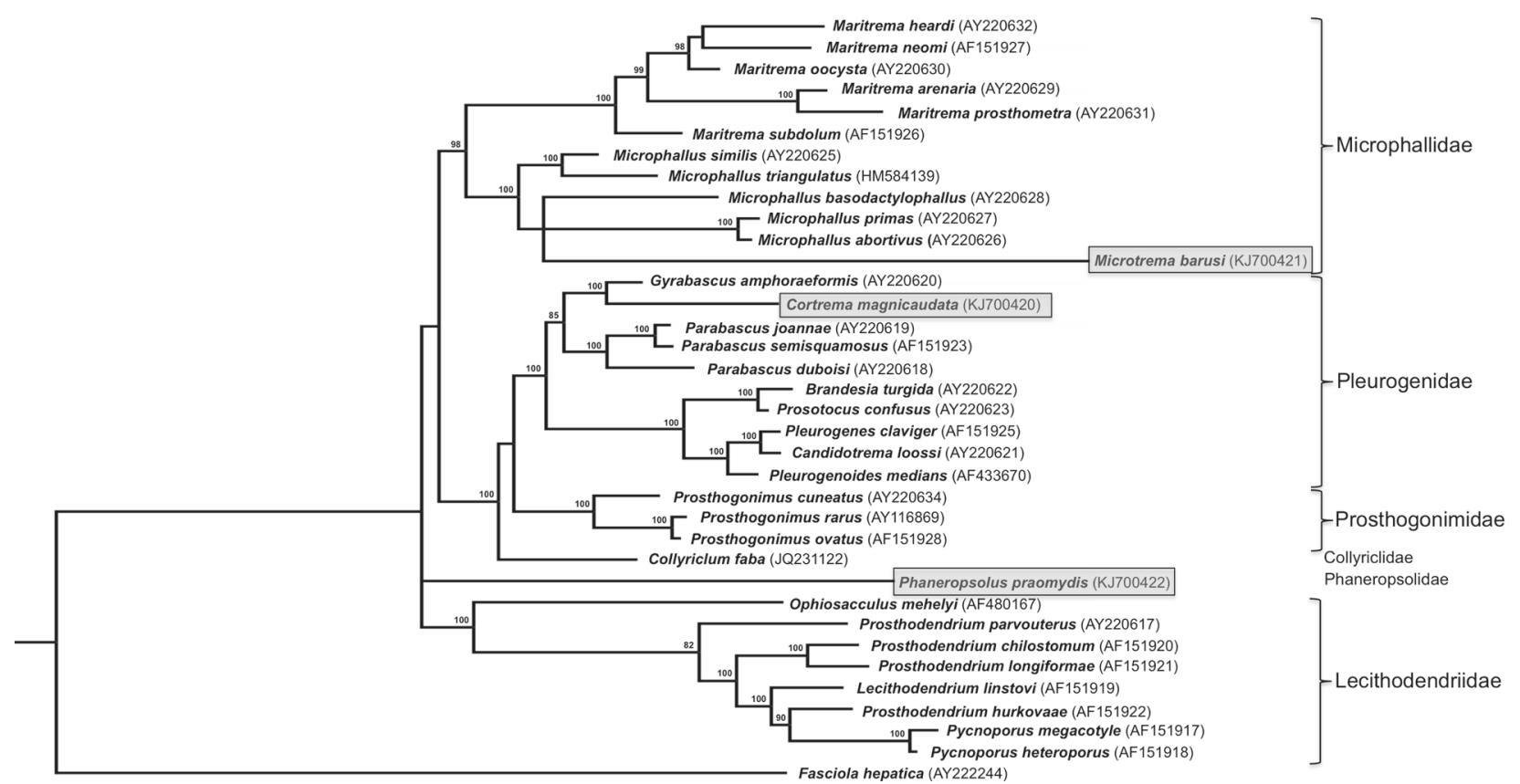

Fig. 1. Phylogenetic relationships among 35 taxa of the Microphalloidea (Digenea) resulting from Bayesian analysis of partial sequences of the $28 \mathrm{~S}$ rRNA gene. Posterior probabilities greater than $80 \%$ are shown above internodes. Shaded rectangles indicate the taxa sequenced and discussed in the present paper.

ase from EurX (Gdańsk, Poland) according to manufacturer's instructions. Annealing temperature during the thermal cycling was $52^{\circ} \mathrm{C}$. The PCR products were purified using QIAquick PCR purification Kit (Qiagen) and sequenced in both directions (Genomed S.A., Warsaw, Poland). The obtained sequences were deposited in GenBank under the following accession numbers: KJ700420 (Cortrema magnicaudata), KJ700421 (Microtrema barusi) and KJ700422 (Phaneropsolus praomydis).

\section{Alignment and phylogenetic analyses}

A BLAST search (www.ncbi.nih.gov/BLAST) of the GenBank database has demonstrated that the sequence of C. magnicaudata was closest to multiple representatives of the superfamily Microphalloidea with a very high degree of similarity. Therefore, the alignment used in the phylogenetic analysis included previously published sequences of a variety of the Microphalloidea (Tkach et al. 2000, 2001, 2003). In addition, sequences of Phaneropsolus praomydis (KJ700422), Microtrema barusi (KJ700421) and Collyriclum faba (JQ231122) have been added to the alignment. Sequences were aligned using the on-line version of software MAFFT ver. 7 (www.mafft.cbrc.jp) with the option FFT-NS-1. The phylogenetic analysis was performed using Bayesian inference (BI) as implemented in the MrBayes ver. 2.01 software (Huelsenbeck and Ronquist 2001). Based on the topologies in the previously published phylogenetic trees of the Digenea, sequence of Fasciola hepatica Linnaeus (AY222244) was chosen as an outgroup. Bayesian inference was employed using the following nucleotide substitution parameters: $n s t=6$, rates=invgamma, that correspond to a general time reversible model (GTR) including estimates of the proportion of invariant sites (I) and gamma distribution (G). Posterior probabilities were approximated over 1000000 generations, log-likelihood scores plotted and only the final $75 \%$ of trees were used to produce the consensus trees by setting the 'burnin' parameter at
250000 . This number of generations was sufficient because the standard deviation dropped well below 0.01 at the end of the run.

\section{RESULTS}

The final alignment of the $\operatorname{sr} D N A(\mathrm{n}=36)$ fragment was 1224 bp long with 550 variable characters. The BI analysis resulted in a tree with ingroup taxa divided into six family-level clades (Fig. 1). The tree topology strongly resembled the results from the previous phylogenetic study of the Microphalloidea by Tkach et al. (2003), with the exception of the clades of Phaneropsolus Looss, 1899 and Collyriclum, which were lacking in the mentioned phylogeny.

The first clade representing members of the family Lecithodendriidae (Fig. 1) was 100\% supported by BI, with very strongly supported internal topology within the family. The family Phaneropsolidae Mehra, 1935, represented in our study by $P$. praomydis, appeared as a separate branch not showing close affinities with any other family-level lineage. Three families, namely the Collyriclidae, Prosthogonimidae and Pleurogenidae, formed a $99.9 \%$ supported clade. The interrelationships among the three families remained essentially unresolved due to the low posterior probability value at the node uniting the Prosthogonimidae and the Pleurogenidae (Fig. 1). However, the internal interrelationships within both the Pleurogenidae and the Prosthogonimidae were very well resolved.

Cortrema magnicaudata appeared among the pleurogenid taxa and clustered in a $100 \%$ supported clade with 
Gyrabascus amphoraeformis (Modlinger, 1930) (Fig. 1). This clade clustered with three members of Parabascus Looss, 1907. The second, 100\% supported, large clade within the Pleurogenidae united genera Brandesia Stossich, 1899, Candidotrema Dollfus, 1951, Pleurogenes Looss, 1896, Pleurogenoides Travassos, 1921 and Prosotocus Looss, 1899, all parasites of amphibians. Finally, the last family level group included members of the family Microphallidae with high level of support of practically all of its internal groupings. Microtrema barusi sequenced in this study was placed by our analysis in the Microphallidae, nested among several species of Microphallus (Fig. 1).

\section{DISCUSSION}

As described in the Introduction, the systematic and taxonomic history of Cortrema was extremely complex. Different authors included it in the Troglotrematidae, Lecithodendriidae or its own family within superfamilies Troglotrematoidea, Lecithodendrioidea or Gorgoderoidea (see references in the Introduction). Our study has revealed the phylogenetic affinities of Cortrema and allowed to define its correct systematic position. The phylogenetic analysis inferred from the 28S rRNA gene ( $\operatorname{srDNA}$ ) sequences has demonstrated that this genus belongs to the family Pleurogenidae within the superfamily Microphalloidea, which largely corresponds to the Lecithodendrioidea in the system of Odening (1964a).

Our results refute the placement of the Cortrematidae among the families of the Gorgoderoidea Looss, 1899 proposed in the latest systematic arrangement of the group (Lotz and Font 2008a). In the phylogenetic tree (Fig. 1) Cortrema is closest to the genus Gyrabascus Macy, 1935 among currently sequenced taxa. The two genera share several important morphological characteristics. Both Cortrema and Gyrabascus share the I-shaped excretory vesicle, pretesticular ovary, lack of a true cirrus-sac, a long winding seminal vesicle freely lying in parenchyma and both genera are devoid of a visible pars prostatica. Because of this phylogenetic placement of its type and only genus, the family Cortrematidae should be considered among synonyms of the Pleurogenidae. Even if the Gyrabascidae would be considered as an independent family, the name Cortrematidae would be suppressed as its junior synonym.

Tang and Tang (1981) described sporocysts and nonvirgulate xiphidiocercarie of $C$. corti (considered here a synonym of $C$. magnicaudata, see the discussion below) developing in pulmonate snails Lymnaea (Fossaria) ollula Gould and Succinea chinensis Pfeiffer. This causes a concern because representatives of the phylogenetically closest Gyrabascus have virgulate xiphidiocercariae parasitic in prosobranch snails (Burns 1961a,b). It should be emphasised, however, that Tang and Tang (1981) used field collected snails for their study. The cercariae described by these authors have a very different excretory vesicle compared to the adult Cortrema (V-shaped or modified Y-shaped as opposed to I-shaped). Besides, their cercariae did not have any caeca whereas the caeca are very well developed and long in adult Cortrema. Tang and Tang (1981) did not complete the life cycle and did not obtain adult digeneans resulting from their infections of field-collected snails with the eggs of Cortrema. In our opinion, the data on cercarial morphology and intermediate hosts presented by Tang and Tang (1981) need to be considered with caution until additional convincing evidence becomes available.

Although we did not have representatives of other species of Cortrema for molecular study, available morphological information allows us to consider their taxonomic status. Based on literature data, C. magnicaudata differs from $C$. corti only in length of the Laurer's canal, not considering small differences in body size. In $C$. corti the canal extends to the end of the body, whereas it opens at the level of the distal end of the testes in the former species (Tang 1951, Khotenovskii 1961). In our opinion, this morphological feature alone is not sufficient for species differentiation. In contrast, $C$. corti seems to occur exclusively in the bursa Fabricii of birds (Tang 1951, Tang and Tang 1981), whereas C. magnicaudata has been reported only from the caeca or distal parts of the intestine (Khotenovskii 1961, Sitko et al. 2006; present data). However, Oshmarin (1970) pointed that site preference in this trematode species is likely to be age-dependent. In young birds these digeneans prefer bursa Fabricii whereas they occur in the caeca in adult birds. Therefore, the difference in the infection site is a rather weak argument in favour of the status of C. magnicaudata and C. corti as separate species.

Interestingly, in another European species, C. testilobata (Bykhovskaya-Pavlovskaya, 1953), the Laurer's canal opens at the level of the distal end of the testes, similar to $C$. magnicauda. The only feature that allows distinguishing these species is the slightly smaller body size of C. testilobata - see Khotenovskii (1961). The taxonomic status of the last described species, C. niloticus, is unclear. The original description was poor and did not contain key morphological details that would justify establishment of a new species (Ashour et al. 1994). Therefore, we consider C. corti, C. testilobata and C. niloticus as junior synonyms of $C$. magnicaudata.

The Pleurogenidae in our phylogeny was clearly monophyletic. However, it contains a genus Parabascus, which was a member of the Phaneropsolidae in the most recent revision by Lotz and Font (2008b). According to the system proposed by these authors, the Phaneropsolidae is a large family including 26 genera of digeneans parasitic almost exclusively in warm-blooded vertebrates, primarily mammals. Recently, Sitko (2013) established a new genus Microtrema Sitko, 2013 for his 
new species Microtrema barusi from passeriform birds in Central Europe. This genus was also included in the Phaneropsolidae (Sitko 2013). Of these 27 genera, only species of Parabascus have been sequenced prior to the present study (Tkach et al. 2002, 2003). Therefore, inclusion of a member of Phaneropsolus in our molecular phylogenetic analysis was important to resolve the problem of the interrelationships between the Pleurogenidae and Phaneropsolidae, and to provide the framework for future detailed analysis and revision of the Phaneropsolidae. It should be mentioned that Phaneropsolus itself was previously included into several family-level taxa, namely the Lecithodendriidae (e.g. Mehra 1935, Baer 1971, Yamaguti 1971, Goodman and Panesar 1986), usually within the subfamily Phaneropsolinae, or the Pleurogenidae (see Khotenovskii 1970, Sharpilo and Iskova 1989), in the latter case as a member of the subfamily Parabascinae.

Our analysis allows us to make two conclusions regarding the status and content of the Phaneropsolidae. First, the status of the Phaneropsolidae as an independent family should be maintained because $P$. praomydis appeared in the phylogentic tree as an independent familylevel branch not showing close relationships with other families of the Microphalloidea. The second conclusion is that Parabascus is not closely related to Phaneropsolus and instead belongs to the Pleurogenidae as was earlier demonstrated by Tkach et al. (2002, 2003).

Sequencing of the remaining genera included in the Phaneropsolidae by Lotz and Font (2008b) is necessary to clarify their phylogenetic affinities and systematic positions. Based on the significant diversity of morphological features among genera currently placed in the Phaneropsolidae we anticipate that some of them will need to be transferred into other families.
Inclusion of both $P$. praomydis and $M$. barusi in the present study also allowed us to analyse the systematic position of Microtrema. In the phylogenetic tree, $M$. $b a$ rusi was nested among several species of Microphallus in a 100\% supported clade (Fig. 1). Therefore, there is little doubt that the genus Microtrema should be synonymised with Microphallus and the status of M. barusi needs to be re-evaluated upon careful morphological re-examination and comparison with members of Microphallus and other genera of the Microphallidae, not the Phaneropsolidae. The rather superficial original description of $M$. barusi does not allow to adequately address this question without morphological re-examination of the type specimens. Among other systematic outcomes, our analysis confirmed the conclusion by Heneberg and Literák (2013) regarding the status of Collyriclidae as a family within the Microphalloidea.

To address the broader questions of the taxonomic composition of the Microphalloidea, representatives of some not yet sequenced families (e.g. Anenterotrematidae, Eumegacetidae, Renschtrematidae, Stomylotrematidae, etc.) need to be sequenced and included in future phylogenetic analyses.

Acknowledgements. The authors are grateful to Thomas Gnoske (The Field Museum, Chicago, USA) and the field crew from the Malawi National Museum for their invaluable help in collecting small mammals in Malawi. We also thank Guo Lei (University of North Dakota, USA) for his kind assistance with translation of the paper by Tang and Tang (1981). This study was supported in part by the National Sciences Foundation award DEB1050525 for VVT and The Field Museum's Emerging Pathogens Project.

\section{REFERENCES}

Ashour A.A., Ahmed S.E., Lewis J.W. 1994: A new species of Cortrema Tang, 1951 (Digenea: Cortrematidae) from the Egyptian sparrow, Passer domesticus niloticus. J. Egypt. Ger. Soc. Zool. 14: 495-502.

BAER J.G. 1971: Trématodes de rongeurs récoltés en Côte d'Ivoire. Z. Parasitenkd. 37: 226-254.

Blair D., BARTon D.P. 2008: Family Cortrematidae Yamaguti, 1958. In: R.A. Bray, D.I. Gibson and A. Jones (Eds.), Keys to the Trematoda, Vol. 3. CAB International and Natural History Museum, London, pp. 231-232.

Bray R.A., Blair D. 2008: Superfamily Gorgoderoidea Looss, 1899. In: R.A. Bray, D.I. Gibson and A. Jones (Eds.), Keys to Trematoda, Vol. 3. CAB International and Natural History Museum, London, pp. 187-90.

BURns W.C. 1961a: Six virgulate xiphidiocercariae from Oregon, including redescriptions of Allassogonoporus vespertilionis and Acanthatrium oregonense. J. Parasitol. 47: 919-925.

Burns W.C. 1961b: Penetration and development of Allassogonoporus vespertilionis and Acanthatrium oregonense (Trematoda: Lecithodendriidae) cercariae in caddis fly larvae. J. Parasitol. 47: 927-932.
Bykhovskaya-Pavlovskaya I.E. 1950: [New species of kidney parasites (genus Renicola) of birds.] Dokl. Akad. Nauk SSSR 71: 412-417. (In Russian.)

Bykhovskaya-Pavlovskaya I.E. 1953: [Trematode fauna of birds of Leningrad region]. In: A.M. Petrov (Ed.), Contributions to Helminthology Published to Commemorate the $75^{\text {th }}$ Birthday of K.I. Skryabin.] Izdatelstvo Akademii Nauk SSSR, Moscov, pp. 85-92. (In Russian.)

Goodman J.D., Panesar T.S. 1986: Phaneropsolus (Phaneropsolus) n. sp. (Trematoda: Lecithodendriidae) from the potto Perodicticus potto in Uganda. Trans. Am. Microsc. Soc. 105: 76-78.

Henneberg P., Literák I. 2013: Molecular phylogenetic characterization of Collyriclum faba with reference to its three hostspecific ecotypes. Parasitol. Int. 62: 262-267.

HuELSENBECK J.P., RonQuist F. 2001: MrBayes: Bayesian inference of phylogeny. Bioinformatics 17: 754-755.

KhotenovskiI I.A. 1961: [Morphology and taxonomy of trematodes of the genus Cortrema Tang, 1951 (Lecithodendriidae Odhner, 1911)]. Parazitol. Sb. 20: 324-338. (In Russian.) 
Khotenovskil I.A. 1970: [Family Pluerogenidae Looss, 1899]. In: K.I. Skryabin (Ed.), [Trematodes of Animals and Man, Vol. XXIII.] Nauka, Moscow, pp. 137-306. (In Russian.)

Lotz J.M., Font W.F. 2008a: Family Gyrabascidae Macy, 1935. In: R.A. Bray, D.I. Gibson and A. Jones (Eds.), Keys to Trematoda, Vol. 3. CAB International and Natural History Museum, London, pp. 523-525.

Lotz J.M., Font W.F. 2008b: Family Phaneropsolidae Mehra, 1935. In: R.A. Bray, D.I. Gibson and A. Jones (Eds.), Keys to Trematoda, Vol. 3. CAB International and Natural History Museum, London, pp. 545-562.

Menra H.R. 1935: New trematodes of the family Lecithodendriidae Odhner, 1911, with a discussion on the classification of the family. Proc. Acad. Sci. Agra Oudh 5: 99-121.

Odening K. 1964a: Zur Taxonomie zur Trematodenunterordnung Plagiorchiata. Monatsber. Deutsch. Akad. Wiss. Berlin 6: 191-198.

ODENING K. 1964b: Exkretionssystem und systematische Stellung einiger Fledermaustrematoden aus Berlin und Umgebung nebst Bemerkungen zum Lecithodendrioiden Komplex. Z. Parasitenkd. 24: 453-483.

Odening K. 1971: Möglichkeiten der Herstellung des bisher unbekannten Zusammenhangs von Cercarien und adulten Trematoden mit Hilfe detaillierter Kenntnisse des Exkretionssystems nebst Ausführungen zum weiteren Ausbau des Systems der Plagiorchiata. Parasitol. Schrift. 21: 57-72.

Olson P.D., Cribb T.H., Tkach V.V., Bray R.A., Littlewood D.T.J. 2003: Phylogeny and classification of the Digenea (Platyhelminthes: Trematoda). Int. J. Parasitol. 33: 733-755.

OshmaRin P.G. 1970: [Trematodes of wild and domestic birds of Democratic Republic of Vietnam.] In: P.G. Oshmarin, Y.L. Mamaev and B.I. Lebedev (Eds.), Helminths of Animals in South-Eastern Asia. Nauka, Moscow, pp. 5-126. (In Russian.)

Received 5 May 2014
Sharpilo V.P., Iskova N.I. 1989: [The Fauna of the Ukraine. Trematoda: Plagiorchiata.] Naukova Dumka, Kiev, 280 pp. (In Russian.)

Siтко J. 2013: Microtrema barusi gen. n. and sp. n. (Digenea: Phaneropsolidae) from Prunella modularis (Aves, Passeriformes) in the Czech Republic. Helminthologia 50: 43-45.

Sitko J., Faltýnková A., Scholz T. 2006: Checklist of the Trematodes (Digenea) of Birds of the Czech and Slovak Republics. Academia, Praha, $111 \mathrm{pp}$.

TANG C.C. 1951: Contribution to the knowledge of the helminth fauna of Fukien. Part 2. Notes on Ornitobilharzia hoeppli n. sp. from Swinhoe's snipe and Cortrema corti n. gen. n. sp. from the Chinese tree sparrow. Peking Nat. Hist. Bull. 19: 209-216.

TANG C.C., TANG Z.Z. 1981: Studies on the life cycle of Cortrema corti Tang. Acta Zool. Sin. 27: 64-74.

Tkach V.V., Littlewood D.T.J., Olson P.D., Kinsella J.M., ŚWIDERSKi Z. 2003: Molecular phylogenetic analysis of the Microphalloidea Ward, 1901. Syst. Parasitol. 56: 1-15.

Tкасн V.V., Lotz J.M., Świderski Z., Esteban J.G. 2002: On the systematic position of Ophiosacculus Macy, 1935 (Digenea: Lecithodendriidae), with erection of the Ophiosacculinae n. subfam. Syst. Parasitol. 53: 159-167.

Tkach V., Pawlowski J., Mariaux J. 2000: Phylogenetic analysis of the suborder Plagiorchiata (Platyhelminthes, Digenea) based on partial lsrDNA sequences. Int. J. Parasitol. 30: 83-93.

Tkach V.V., Pawlowski J., Mariaux J., Świderski Z. 2001: Molecular phylogeny of the suborder Plagiorchiata and its position in the system of Digenea. In: D.T.J. Littlewood and R.A. Bray (Eds.), Interrelationships of the Platyhelminthes. Taylor \& Francis, London, pp. 186-193.

Yamaguti S. 1958: Systema Helminthum. Volume I. The Digenetic Trematodes of Vertebrates. Interscience Publishers Inc., New York, 979 pp.

Yamaguti S. 1971: Synopsis of Digenetic Trematodes of Vertebrates. Vol. I. Keigaku Publishing, Tokyo, 1074 pp.

Accepted 1 July 2014 